\author{
Н. Ю. Авина \\ Университет Vytautas Magnus \\ (Литва, Каунас) \\ natalja.avina@vdu.lt
}

\title{
ОСОБЕННОСТИ СЛОВОИЗМЕНЕНИЯ ИНОЯЗЫЧНОЙ ЛЕКСИКИ (НА МАТЕРИАЛЕ ЛИТОВСКО-РУССКОГО ЯЗЫКОВОГО КОНТАКТИРОВАНИЯ)
}

Активизация употребления иноязычной лексики в русском языке новейшего периода - один из наиболее значимых языковых процессов. В связи с этим вызывает интерес освоение иноязычных слов из определенного языка-источника в различных ситуациях иноязычного окружения. В данной статье представлены некоторые наблюдения, касающиеся особенностей грамматической адаптации иноязычных слов в русской речи в ситуации литовско-русского языкового взаимодействия.

Процесс грамматического освоения литовских субстантивов связан прежде всего со спецификой их склонения, что обусловлено разнообразными факторами, например: морфологической структурой, распространенностью, функционированием в определенной сфере языка и определенной форме, а также традицией употребления и написания иноязычных слов в конкретном печатном издании. Особенности родовой и числовой адаптации литовских слов связаны с их грамматической трансформацией в русском языке.

В ситуации языкового взаимодействия выявляются как общие для современного русского языка, так и специфические черты процесса адаптации иноязычных слов. С одной стороны, активизирующиеся региональные употребления становятся новым источником интенсивного пополнения класса несклоняемых слов, демонстрируя при этом противоречивость проявления тенденции к аналитизму, рост вариативности языковых единиц. С другой стороны, специфика процесса адаптации обусловлена грамматическими особенностями конкретного языка-источника, непосредственным языковым контактированием, особенностями функционирования русского языка в данном социокультурном пространстве. Процесс грамматической адаптации региональных употреблений вызывает проблемы культуры речи; важной для нормативных оценок становится коммуникативная значимость иноязычной лексики.

Ключевые слова: иноязычное слово, словоизменение, грамматическая адаптация, вариативность, языковое контактирование. 


\section{1. Вводные замечания}

Активизация употребления иноязычной лексики в русском языке новейшего периода - один из наиболее живых и социально значимых языковых процессов, требующих углубленного и детального изучения во многих аспектах: лингвистическом, функционально-коммуникативном, когнитивном, социолингвистическом. “< ..> Именно в лексике, - пишет Д.Н. Шмелев, - отражены в первую очередь контакты между различными народами и в лексике же сосредоточено то, что является общим для многих самых различных языков" [Шмелев 1977: 20].

Освоение иноязычной лексики в системе заимствующего языка происходит сложно; каждый язык, выступая в качестве реципиента, вырабатывает свои приемы и способы адаптации иноязычий: фонетические, семантические, словообразовательные, грамматические, графические, орфографические (например, [Хауген 1972: 344-382, Крысин 2004:37-57]). В связи с этим вызывает интерес процесс адаптации иноязычных слов из определенного языка-источника, которые активизируются в русской речи в различных ситуациях иноязычного окружения (см. исследования языка русского зарубежья [Земская 2001: 119-121, 184-208, Гловинская 2001: 437-446 и мн. др.]). В ряду разнообразных вопросов, связанных с освоением иноязычных слов, в нашей работе рассматриваются некоторые особенности словоизменения региональных иноязычий в русской речи в ситуации литовско-русского языкового взаимодействия. Материалом исследования является как устная разговорная речь (преимущественно русских жителей г. Вильнюса), так и письменная литературная речь (в основном - русскоязычные газеты Литвы в период последних десятилетий). В работе приняты следующие сокращения названий газет: ЛК — “Литовский курьер"; ЛР — “Летувос ритас"; Обз. — “Обзор”; Р — "Республика”; Эх.Л. — “Эхо Литвы”; Эк.Н. — “Экспресс-неделя”.

Анализируемые в статье языковые факты - это литовские имена существительные, преимущественно собственные: онимы, топонимы, гидронимы и под., а также имена нарицательные, которые представляют определенные тематические группы слов, связанные с социальными вопросами, бытовыми реалиями, трудовой деятельностью, культурой, образованием. Общность тематических групп субстантивов в русском языке в различном иноязычном окружении, которая подтверждается и нашим материалом, свидетельствует об определенных языковых универсалиях в сфере лексики (см., например, [Земская 2008: 632-646]). Региональные употребления представляют собой как безэквивалентную лексику, так и лексику, имеющую эквиваленты в русском языке.

\section{2. Некоторые особенности словоизменения иноязычных имен существительных}

В современном русском языке процесс грамматического освоения субстантивов связан прежде всего со спецификой их склонения, а с также родовой и числовой адаптацией, что обусловлено разнообразными лингвистическими 
и социолингвистическими факторами; при этом множество иноязычий обнаруживает вариантность по признаку склоняемости/несклоняемости (см. подробнее [Маринова 2008: 125-215]). Наши наблюдения также свидетельствуют о том, что в процессе грамматической адаптации региональных употреблений основные проблемы касаются преимущественно склонения литовских слов в русском языке.

\section{1. Особенности склонения}

Специфика включения региональных употреблений в русскую речь связана с тем, что, будучи склоняемыми в литовском языке, в русской речи они часто характеризуются непоследовательностью словоизменения. Выделим основные факторы, обусловливающие склоняемость/несклоняемость определенных иноязычий, хотя в целом эта дифференциация весьма условна.

Важным фактором склоняемости/несклоняемости иноязычий является их морфологическая структура, определенный исход слова. Назовем некоторые типичные группы литовских слов как устойчиво склоняемых, так и устойчиво несклоняемых в разных сферах функционирования русского языка.

Иноязычия обычно изменяются, если финаль литовского слова соотносится с формой русского слова и совпадают формы рода, числа русского и литовского слова. При этом происходит родовая и числовая адаптация иноязычного слова. Отметим региональные иноязычия, преимущественно склоняемые в русском языке:

существительные мужского рода на $-a s$, $-i s,-u s$ с исходом на согласный: Ocoбые закуски, например, “Охотничья” - шедевр из грудинки, кумписа, огурчиков, лучка и хренка (ЛК, № 6, 2005) (kumpis «окорок»); В этом году на Сабантуй в Висагинасе приехали татары из Алитуса < .. > (Обз., № 21, 2018) (Visaginas, Alytus); В этом случае на столе можно увидеть <..> и даже приготовленные для каждого гостя маленькие шакотисы (Эк.Н., № 22, 2018) (糸otis «торт»); в разговорной речи: Нужно сходить к назначенному сенюнасу (лит. seniūnas «староста»); Там сейчас ишпардавимасы большие (išpardavimas «распродажа»);

существительные женского рода с исходом на гласный - $а$ : Покупатели приезжают не только в питомник, но и в 12 лесничеств, принадлежаших Вильнюсской уредии (Эк.Н., № 51, 2009) (urèdija «лесничество»); Не дали результатов и требования Тарибы (Эк.Н., № 7, 2018) (Тaryba «Совет»); в разговорной речи: Саскайту должны скоро прислать (sąskaita «счет»); Бегу на паскайты, опаздывать нельзя (paskaita «лекция»). Как показывает наш материал, иноязычия в форме женского рода многочисленны; между тем в русском языке новейшего периода в ряду иноязычных субстантивов значительно преобладают существительные мужского рода, и это объясняется заимствованием из одного языка-источника - английского [Маринова 2011: 401].

Отметим региональные иноязычия, преимущественно несклоняемые в русском языке:

существительные с исходом на $-\dot{e}$, которые в литовском языке являются словами женского рода: Продается дом в Вильняус Ерузале (Р, 13.05.2009) (Jeruzalè); 
в разговорной речи: Добиралась из Шешкине на автобусе (Šeškinè); Встречаемся около савивальдибе (savivaldybe் «самоуправление»);

существительные в форме множественного числа:

женского рода с исходом на -os (-ès):Магазину торговой сети IKI в Григишкес $<$ _..> требуются: кассиры продавиьь> _..>(Обз., № 21, 2018) (Grigiškès); в разговорной речи: На Каледос приеду (Kalėdos «Рождество»);

мужского рода с исходом на -(i)ai: Постоянно действуют курсы массажа <...> в Вильнюсе, Висагинасе, Панявежисе, Шяуляй< .. >(ЛК, № 39, 2007) (Šiauliai); Heдовольны городским освещуением и жители Лаздинай (Эк.Н., № 6, 2018) (Lazdynai).

Однако в разговорно-бытовой ситуации наблюдается склоняемость подобных иноязычий, например, с финалью на -еं: Возьми с собой тапатибес кортялю $и$ фотографию (tapatybès kortelè в значении «удостоверение личности»); $К$ бабушке в Плунгу ездили (Plungè); Mbl тоже часто вспоминаем и вас, и Бирутю (Birutè); с финалью на -(i)ai: Наша экспедиция проходила под Зарасаем (Zarasai); Жила в Шяуляе, в районе Дайняе (Šiauliai, Dainiai). В разговорной речи в грамматических формах множественного числа на -е́s (-os), -iai может происходить замена литовского окончания и, соответственно, изменение слова по русской грамматической модели. Ср.: в литературной речи: Для решения проблем стоянки автомобилей в Сантаришкес будут платные места <...> (ЛК, № 18, 2009) и в разговорной речи - Сантариики, а также Сантары (топоним Santariškès); подобная русифицированная форма отмечается и в текстах газет: Продается новый дом в Швейцарах <..> с частичной отделкой (Эк.Н., № 15, 2010) (Šveicarai). Следовательно, одним из важных факторов изменяемости/неизменяемости иноязычий является их функционирование в определенной сфере языка.

Изменяемость региональных иноязычий зависит также от их функционирования в определенной форме речи. В письменной речи более распространены несклоняемые варианты: 70\% акций «Летувос драудимас» принадлежит датской страховой компании <...> (Эх.Л., №209, 1999); Сдается 1-комнатная квартира $<\ldots>$ по Эйшишкю плянтас (Обз., № 12, 2002). Однако это происходит непоследовательно, ср. склонение подобных составных названий: $B$ Вильнюсе изделия "Жемайтийос пенаса" из-за транспортных расходов подскочили в иеене почти на 5 процентов (ЛР, №2, 1999); Ценнье бумаги правительства можно купить в Сбербанке, «Жямес уке банкасе», «Гермисе», «Укё банкасе» < .. > (ЛР, 1999).

Существенными в письменной речи оказываются традиции изменения/неизменения иноязычных слов в том или ином печатном издании. Так, литовские слова женского рода с исходом на - оji устойчиво не склоняются в русском языке; см., на-

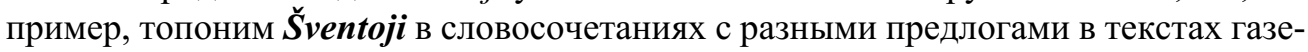
ты «Экспресс-неделя»: Отдых с удобствами в Паланге и Швентойи (Эк.Н., №24, 2012); О Швентойи забыли на два с лишним столетия (Эк.Н., № 11, 2018); <..> Возле Швентойи располагается нефтетерминал (Эк.Н., № 11, 2018). Но ср. изменяемость слова в другой газете - «Литовский курьер»: 8 дней отдыха в Швенmoйe «Vaivorykštè» (удобства, автобус, проживание, завтраки) (ЛК, № 30, 2009). Кроме того, в разных печатных изданиях литовские названия могут использоваться 
в разных формах языка-источника: в форме именительного падежа: $B$ парке Сяряйкишкес <..> обновлено освещение, приводятся в порядок газоны (Эк.Н., № 25, 2009) (Sereikiškès), в форме родительного падежа: Приглашаем на праздник в вильнюсском парке “Серейкишкю» (ЛК, № 21, 2007) (Sereikiškiu).

Изменяемость/неизменяемость иноязычий в печатном издании может быть обусловлена использованием определенной графики. Написание в оригинальной графике латиницей, в отличие от кириллического варианта написания, предполагает, естественно, несклоняемость вкрапления в тексте, ср.: Польша уже жалеет, что купила "Mažeikiч nafta» (Обз., № 21, 2009); но: <...>генеральный директор «Мажейкю нафты» < ...> (P, 21.05.2009); По адресу: ул. Миндауго (около “МАХІМА») (Эк.Н., № 50, 2009), но: Продается 1-комнатная квартира в Науйининкай (рядом c «Максимой») (Эк.Н., № 34, 2011).

Необходимо назвать еще один важный фактор изменяемости иноязычий, который обычно действует в процессе заимствования и носит универсальный характер: актуальность реалии, обозначаемой словом, и, соответственно, широкая распространенность такого иноязычия. Это касается прежде всего безэквивалентной лексики. Яркий пример грамматической адаптации литовского слова - слоговая аббревиатура Sodra (socialinis draudimas «социальное страхование»), склоняемая в русском языке, хотя графическое и орфографическое оформление этого слова

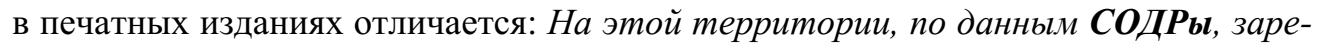
гистрировано 45 mысс. предприятий <... (ЛК, №9, 1999); <..> исправно выплачивая государству и СОДРЕ все налоги (ЛК, № 15, 2010); <..> идея сократить взносы в “Содру» исходит от бизнеса (ЛК, № 21, 2018); отмечаются также производные слова: Это не весь содровский список (ЛК, № 5, 2018).

\section{2. Особенности грамматических форм рода и числа}

Отметим некоторые факты грамматической трансформации в русском языке форм числа литовских слов. Так, название района Šnipiškès в форме множественного числа женского рода может использоваться в русском языке в форме единственного числа мужского рода: Шнипишкес был известен и своей военной истоpией (Эк.Н., № 4, 2018). Система окончаний, как известно, может присоединяться к форме множественного числа иноязычного слова; например, название «Lietuvos dujos» («Литовский газ») с опорным словом на -os в форме множественного числа может изменяться в русском языке по соответствующему типу склонения как форма единственного числа: < ..> Возврат долга от «Литовского дуеса» <...> (Обз., №38, 1999).

В качестве иллюстрации переосмысления грамматической формы рода приведем название реки Neris. В литовском языке это слово женского рода, но в русском языке используется как слово мужского рода с финалью на твердый согласный: Сейчас сложно представить, но примерно тысячу лет назад Нярис протекал y самого подножия горы Таурас (Эк.Н., №4, 2018); отмечается также несклоняемость данного слова: <..> Они подарили участок рядом с Нярис (Эк.Н., №4, 
2018). Другой пример - топоним $\breve{S} \boldsymbol{v e n t o j i , ~ п р е д с т а в л я ю щ и и ̆ ~ с о б о и ̆ ~ ф о р м у ~ ж е н с к о - ~}$ го рода в литовском языке, который используется в форме мужского рода в русском языке (по опорному слову «город»): Швентойи опять на два с лишним десятилетия погрузился в забвение (Эк.Н., № 11, 2018).

Любопытным представляется и смешение форм рода в следующем контексте: Bom эта suknel⿱亠凶禸 серенькая очень симпатичное (suknelè «платье» - женск. $p$.). Региональные инновации выступают как этнокультурный компонент речевой коммуникации, и специфика процесса их грамматической адаптации отражает определенные особенности языкового сознания билингвов, обусловленные коммуникативной целесообразностью.

\section{3. Заключительные замечания}

В ситуации иноязычного окружения в процессе грамматического освоения региональных употреблений выявляются как общие для современного русского языка, так и специфические черты адаптации иноязычий.

Общие черты связаны с тем, что в русском языке новейшего периода отмечается активизация иноязычных имен существительных, обнаруживающих тенденцию к несклоняемости; этот процесс, однако, протекает неравномерно, появляются варианты, обусловленные коммуникативной потребностью [Гловинская 2008: 227-236]. Вариативность иноязычных слов отличается особой спецификой, что связано с процессом их адаптации к языковой системе, в которой им предстоит функционировать. Исследователи русского языка зарубежья отмечают еще более активный, в сравнении с исконной средой, характер проявления аналитических черт в речевой практике коммуникантов: увеличение количества несклоняемых слов, прежде всего имен существительных, которые активно заимствуются из языка-источника и в разной степени подвергаются грамматическому оформлению по законам русского языка [Земская 2001: 200-208]. При этом ускоряются «процессы включения и освоения иноязычных слов, фразем в речевую практику, часто растянутые в языке метрополии на диахронической оси» [Зеленин 2007:252]. Региональные иноязычия, активизирующиеся в ситуации литовско-русского языкового контактирования, также становятся новым источником быстрого и интенсивного пополнения класса несклоняемых слов, демонстрируя при этом противоречивость проявления тенденции к аналитизму, усиление вариативности языковых единиц в русском языке в данной социокультурной среде.

Специфические черты процесса грамматического освоения анализируемых региональных иноязычий обусловлены как лингвистическими факторами, в частности, грамматическими особенностями конкретного языка-источника в конкретной ситуации иноязычного окружения, так и экстралингвистическими факторами, прежде всего социолингвистическими и социокультурными, связанными с непосредственным языковым контактированием и особенностями функционирования русского языка в данном этнокультурном пространстве. 
Результатом процесса адаптации должно стать стабильное функционирование иноязычий как полноправных единиц системы, но их освоение происходит сложно и, судя по нашему материалу, в настоящий период трудно определить закрепленность в русском языке тех или иных грамматических форм. Нельзя не согласиться с тем, что «заимствования в русский язык, происходящие за пределами России, не всегда следуют тем же правилам, что заимствования из иных языков во внутрироссийском употреблении. <..> Приходится исходить уже не только из норм русского языка, но также из матрицы доминирующего в окружении иного языка, из образа мыслей и стиля существования, отличающихся от российских. <..> Происходит работа по самоопределению, в том числе и языковому» [Протасова 2000: 59].

Неунифицированность и непоследовательность грамматической адаптации региональных употреблений обычно не вызывает у русскоговорящих в данной социокультурной среде серьезных коммуникативных помех, связанных с неадекватным восприятием и пониманием речи, но создает определенные культурно-речевые проблемы, приводящие, возможно, к расшатыванию норм русского литературного языка. Необходимость постоянно передавать на письме названия реалий конкретной языковой ситуации приводит к тому, что региональные понятия нормы и отступлений от нормы литературного языка несколько иные, нежели в исконной среде. Важной для нормативных оценок становится коммуникативная значимость языковых единиц. «Употребление иноязычного слова диктуется потребностью в точности, в том, чтобы быть сразу понятым. Кроме того, говорящий постоянно слышит и видит местные номинации для обозначения местных реалий; естественно, что они первыми приходят ему в голову, когда речь идет об окружающей его жизни. Таким образом, одна из причин возникновения заимствований из языка окружения состоит в экономии усилий обоих (или более) партнеров по коммуникации» [Гловинская 2001: 438]. В связи с этим следует отметить важность кодификации литературной нормы русского языка в ситуации иноязычного окружения, создания словарей и справочников по употреблению региональных инноваций, дальнейшей разработки соответствующего материала в учебниках, предназначенных для изучения русского языка в конкретной этнокультурной ситуации.

\section{Литература}

Гловинская М. Я. Общие и специфические процессы в языке метрополии и эмиграции // Язык русского зарубежья. Общие процессы и речевые портреты. Коллективная монография / отв. редактор Е.А. Земская. М. - Вена: Языки славянской культуры: Венский славистический альманах, 2001. С. 341-492.

Гловинская М.Я. Активные процессы в грамматике // Современный русский язык. Активные процессы на рубеже XX-XXI веков / отв. ред. Л. П. Крысин. М.: Языки славянских культур, 2008. С. 187-267.

Зеленин А. Язык русской эмигрантской прессы (1919-1939). СПб: Златоуст, 2007. $380 \mathrm{c}$. 
Земская E. А. Общие языковые процессы и индивидуальные речевые портреты // Язык русского зарубежья. Общие процессы и речевые портреты. Коллективная монография / отв. редактор Е.А. Земская. М. - Вена : Языки славянской культуры: Венский славистический альманах, 2001. С. 25-277.

Земская E.A. Активные процессы в языке русского зарубежья // Современный русский язык. Активные процессы на рубеже XX-XXI веков / отв. ред. Л. П. Крысин. М. : Языки славянских культур, 2008. С. 615-669.

Крысин Л. П. Русское слово, свое и чужое. Исследования по современному русскому языку и социолингвистике. М. : Языки славянской культуры, 2004. 888c.

Маринова Е. В. Иноязычные слова в русской речи конца XX — начала XXI в.: проблемы освоения и функционирования. М. : ООО «Издательство ЭЛПИС», 2008. 495 с.

Маринова E. B. Адаптация иноязычной лексики на современном этапе: новые явления и тенденции // Вестник Нижегородского университета им. Н. И. Лобачевского. T.1. 2011. №6(2).C. 399-403. [Электронный pecypc]. URL: https://cyberleninka. $\mathrm{ru} /$ article/n/adaptatsiya-inoyazychnoy-leksiki-na-sovremennom-etape-novye-yavleniyai-tendentsii

Протасова Е.Ю. Лексические особенности русскоязычной прессы в Германии // Известия АН. Серия литературы и языка. Т.59. М., 2000. № 4. С. 49-60.

Хауген Э. Процесс заимствования // Новое в лингвистике. Языковые контакты. Вып. 6. М. : Прогресс,1972. С. 344-382.

Шмелев Д.Н. Современный русский язык. Лексика. М. : Просвещение, 1977. $335 \mathrm{c}$.

\author{
N. Yu. Avina \\ Vytautas Magnus University \\ (Lithuania, Kaunas) \\ natalja.avina@vdu.lt
}

\title{
PECULIARITIES OF INFLECTION OF FOREIGN-LANGUAGE VOCABULARY (AS EXEMPLIFIED IN THE LITHUANIAN-RUSSIAN LANGUAGE CONTACTING)
}

The activating of the use of foreign-language vocabulary in the contemporary Russian language is one of the most significant linguistic processes. In connection with this, acquisition of foreign language words from some certain source language attracts interest in diverse situations of a foreign-speaking environment. This article presents observations concerning the peculiarities of the grammatical adaptation of foreign-language words in the Russian speech in the situation of the Lithuanian-Russian linguistic interaction.

The process of grammatical acquisition of Lithuanian nouns is primarily related to the specifics of their declension, which is due to a variety of factors, for example, the morphological structure, prevalence, function in a certain sphere of language and in some form, as well as the tradition of using and writing of foreign words in some particular 
printed sources. The peculiarities of the generic and numerical adaptation of the Lithuanian words are related to their grammatical transformation in the Russian language.

The situation of foreign-speaking environment reveals both such features of the process of adaptation of foreign-language words that are general for the modern Russian language and the specific ones. On the one hand, intensifying regional uses become a new source of intensive replenishment of the class of indeclinable, demonstrating at the same time the contradictory tendency of manifestation of analyticism, growth of variability of language units. On the other hand, the grammatical features of a particular source language, direct language contacts and the peculiarities of functioning of the Russian language in this socio-cultural space determine the specificity of the process of adaptation. The process of grammatical adaptation of regional uses causes problems of the culture of speech; the communicative significance of the foreign-language vocabulary becomes important for normative evaluations.

Keywords: foreign-language word, inflection, grammatical adaptation, variability, language contacting.

\section{References}

Glovinskaya M. Ya. [General and specific processes in the language of the mother country and emigration]. Yazyk russkogo zarubezh'ya [Language of the Russian Emigration]. E. A. Zemskaya (Ed.). Moscow — Vien: Yazyki slavyanskoi kul'tury Publ., 2001, pp. 341-492. (In Russ.)

Glovinskaya M. Ya. [Active processes in grammar].Sovremennyi russkii yazyk. Aktivnye protsessy na rubezhe $X X-X X I$ vekov [The Modern Russian Language. Active Processes at the Turn of the 20th-21st cent.]. L. P. Krysin (Ed.). Moscow: Yazyki slavyanskikh kul'tur Publ., 2008, pp. 187-267. (In Russ.)

Zelenin A. Yazyk russkoi emigrantskoi pressy (1919-1939). [The language of the Russian emigrant press (1919-1939)]. St. Petersburg, Zlatoust Publ., 2007. 380 p.

Zemskaya E. A. [General language processes and individual speech portraits]. Yazyk russkogo zarubezh'ya [The language of the Russian emigration]. E. A. Zemskaya (Ed.). Moscow - Vien: Yazyki slavyanskoi kul'tury Publ., 2001, pp. 25-277. (In Russ.)

Zemskaya E. A. [Active processes in the language of Russian abroad]. Sovremennyi russkii yazyk. Aktivnye protsessy na rubezhe XX-XXI vekov [The Modern Russian Language. Active Processes at the Turn of the 20th-21st cent.]. L.P. Krysin (Ed.). Moscow: Yazyki slavyanskikh kul'tur Publ., 2008, pp. 615-669. (In Russ.)

Krysin L.P. Russkoe slovo, svoe i chuzhoe. Issledovaniya po sovremennomu russkomu yazyku i sotsiolingvistike. [The Russian word, of the insiders and of the outsiders. Studies on the contemporary Russian language and sociolinguistics]. Moscow: Yazyki slavyanskoi kul'tury Publ., 2004. 888 p.

Marinova E. V. Inoyazychnye slova $v$ russkoi rechi kontsa XX - nachala XXI v.: problemy osvoeniya i funktsionirovaniya [Foreign words in Russian speech of the late 20th century - early 21st century: problems of adaptation and functioning]. Moscow: OOO «Izdatel'stvo ELPIS» Publ., 2008. 495p. 
Marinova E. V. [Adaptation of foreign-language vocabulary at the present stage: new phenomena and tendencies].Vestnik Nizhegorodskogo universiteta im. N.I. Lobachevskogo. T.1. 2011. № 6 (2), pp. 399-403. (In Russ.)Available at: https://cyberleninka. $\mathrm{ru} /$ article/n/adaptatsiya-inoyazychnoy-leksiki-na-sovremennom-etape-novye-yavleniyai-tendentsii (accessed 4.06.2018)

Protasova E. Yu. [Lexical peculiarities of the Russian-language press in Germany]. Izvestiya AN. Seriya literatury i yazyka. T.59. Moscow, 2000, №4, pp. 49-60. (In Russ.)

Khaugen E. [The process of borrowing].Novoe v lingvistike. Yazykovye kontakty. Vyp. 6.[New in linguistics. Language contacts]. Moscow: Progress Publ., 1972, pp. 344-382. (In Russ.)

Shmelev D. N. Sovremennyi russkii yazyk. Leksika [The Modern Russian Language. Vocabulary]. Moscow: Prosveshchenie Publ., 1977. 335 p. 